\title{
ASSESSMENT OF ECONOMIC SECURITY OF ENTERPRISES: THEORETICAL AND METHODOLOGICAL ASPECTS
}

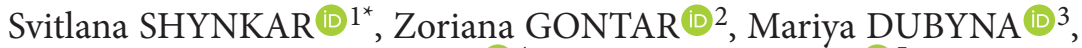 \\ Daria NASYPAIKO (1) 4 , Mariya FLEYCHUK (1) 5 \\ ${ }^{1}$ Department of Finance, Banking and Insurance, King Danylo University, Ivano-Frankivsk, Ukraine \\ ${ }^{2}$ Department of Law and Law Management in the Field of Civil Protection, \\ Lviv State University of Security Life Activity, Lviv, Ukraine \\ ${ }^{3}$ Stephan Gzhytskyi Lviv National University of Veterinary Medicine and Biotechnologies, Lviv, Ukraine \\ ${ }^{4}$ Department of International Economic Relations, Central Ukrainian National Technical University, Lviv, Ukraine \\ ${ }^{5}$ High School of Enterprise and Administration in Lublin, Poland
}

Received 20 November 2019; accepted 9 February 2020

\begin{abstract}
The main objective of the study is to formulate a new approach of assessing economic security for industrial enterprises, indicating a different approach from existing ones, to allow for the very specifics of economic activity, and to allow the use of qualitative and quantitative indicators. We justified that the effectiveness of ensuring the economic security for industrial enterprises is determined by the quality of the information basis for the actions of security entities. A methodological approach is proposed that provides for the determination of the security level at three levels: "indicator functional component - financial indicator" and allows to obtain reliable information about the economic security of oil and gas, engineering and food industries by taking into account the specifics of their economic activities.
\end{abstract}

Keywords: security, economic security, enterprise, assessment of economic security, assessment.

JEL Classification: B49, C10, C13, D21, M20, M41.

\section{Introduction}

Uncertainty of changes in the functioning environment caused by political and social tensions, invariably high fiscal pressure and corruption of local authorities, growing competition from foreign producers and the difficulty of entering new markets due to protectionist measures of importing countries, declining welfare of the population and growing rates of labour migration, requires the implementation of extremely flexible management of industrial enterprises. Such flexibility requires timely, reliable, complete and comprehensive information about changes in internal processes as the basis for taking adequate protective measures in the economic security system of the enterprise.

Information as a set of data on the state and changes in the internal and external environment in the economic security system of the enterprise is used to study, evaluate and analyse economic phenomena and processes in order to develop and make managerial decisions to ensure the level of security necessary for the existence and development. The economic security management of the enterprise is a continuous process (from the foundation to the liquidation of the enterprise) of monitoring the operational environment in order to identify the influence of all factors on the security level as the basis for the development, implementation and control of each management decision within the enterprise.

The internal trap is characterized by a significant number of changes, but all of them indicate the emergence and intensification of the negative impact of threats on the economic security of the enterprise. To make managerial decisions in the economic security system of the enterprise, it is important to create an assessment system that allows to respond only to significant changes, that is, those affect the functioning and development of the location. The significance of changing the parameters of the functioning of the enterprise is indicated by the growth or decrease of a certain indicator, which for security personnel acts as a kind of "litmus paper", which is signalled to the need for a response and the importance of the development and implementation of protective measures. Due attention to

${ }^{*}$ Corresponding author. E-mail: svetlana_kuprik@i.ua 
the creation and systematic improvement of the system for assessing the economic security of an enterprise is necessary to satisfy the information needs of security entities, and significantly affects the effectiveness of their actions.

The main goal of the study is to formulate a methodological approach of assessing the economic security of industrial enterprises, which, unlike existing ones, will take into account the specifics of economic activity and differences in ensuring the economic security of oil, engineering and food industry enterprises, as well as provide for the use of a system of indicators for qualitative and quantitative characteristics security level and their integration into functional groups will become the basis for calculating the integration index level and dynamics is the basis for the formation and changes in the existing organizational and economic mechanism of ensuring the economic security of industrial enterprises.

\section{Literature review}

The issue of ensuring and assessing the safety of the enterprise today is one of the important objects of research by many scientists (Franchuk et al., 2020; O. Biliomistniy, I. Bilomistna, \& Galushko, 2017; Burkaltseva et al., 2017; Britchenko et al., 2018).

Modern scientific researches of problems of providing and assessing the security of the enterprise have significantly expanded and cover more and more components of the economic security itself. For example, Sylkin et al. (2019) and Wu and Meng (2019) determined the place and role of management in the context of security.

In terms of economic security, its formation and organizational support have been investigated by Khalina et al. (2019).

In general, the problems of assessing the economic security of the enterprise have not offended attention among scientists. The results of our previous research are based on a thorough analysis of the remains of scientific research by leading scientists (Stavytskyi, 2017; Bublyk et al. 2017; Avanesova \& Chuprin, 2017; Ianioglo \& Polajeva, 2017; Zhivko, 2013; Menggang, 2013).

The results of familiarization with the scientific work of famous scientists made it possible to identify a number of key obstacles for the organization and implementation of assessments in the context of a particular enterprise, which can be considered signs of a significant problem requiring immediate solution.

The first approach is the indicator one, whose supporters are Arefieva and Kuzmenko (2005), Bendikov and Khrustalev (1999), Blank (2004), Ortinsky, Kernitsky, and Zhivko (2009) and others. The essence of this approach can be defined as follows: actual values of key indicators characterizing various aspects of the enterprise's economic activity are compared with predefined indicators of the level of economic security. A significant deviation of the actual values from the level of the indicator indicates an increase in the level of danger.
The second approach is economic-mathematical, the creators of which are Kovalev and Pletnikova (2000), which provides for the calculation of the function of the dependence of the level of economic security of the enterprise on individual indicators.

The third approach is resource-functional, which today has the largest number of supporters (Pokropivny, 2000). The basis is the structuring of enterprise security by functional components and the determination of a number of indicators characterizing the efficiency of resource use relative to each such component. It is important that this approach allows to determine the integral indicator taking into account the share of each indicator in the group and each group in the overall structure.

The fourth - income-investment, the creation of which Kozachenko (2013) joined, determines the level of profit, that is, net profit, as a key criterion for economic security, enterprise can reinvest in the form of an investment.

Fifth - economic efficiency, the authorship of Bandurka et al. (2003), who hold the view that economic security is determined by the degree to which the enterprise has achieved its planned development indicators, that is, it is an elementary comparison of the actual value of the selected set of indicators with planned.

Sixth - on the basis of financial stability, which was proposed by Ilyashenko (2002), the essence of which is to calculate a number of key indicators characterizing the financial stability of the enterprise, in the future it identifies five basic levels of security: "absolute", "normal", "shaky", "critical" and "crisis".

The seventh - point assessment, which is determined on the basis of familiarization with the scientific works of Evdokimov, Mizin, and Borodina (2002), provides for the selection of indicators, the determination of their limiting values and assessment in accordance with the possibility of accruing a certain number of points for each of certain levels, hereinafter summation and calculation of the integral indicator.

Eighth - program-oriented management and development, to the formation of which Zabrodsky and Kizim (2000) joined. This approach involves the combination of multiple integration of indicators characterizing the economic activity of the enterprise.

Sitdikova and Starodumova (2019) in the context of assessing economic security, examined the main corporate problems that may arise in ensuring security.

Kljucnikov, Mura, and Sklenar (2019) examined information support for security and how to protect information related to the economic activity of an enterprise.

Jankelova et al. (2018) made a good contribution to the development of security assurance and assessment in business organizations in the context of preventing an economic crisis.

An important component of economic security and its financial component, without which it is impossible to effectively assess its condition. In more detail, it was the financial aspect of economic security that Farber (2018) investigated. 
In addition to the approaches briefly described above, others are known, but they are a certain combination of those already considered, or not yet received wide distribution and recognition in the scientific community. In addition to the essence of each of the approaches, we consider it appropriate to note that their application is characterized by a number of disadvantages.

There is no doubt that it is impossible to avoid all the identified shortcomings, because the presence of some of them is due to inconsistency of opinions regarding the essence and key tasks of the economic security of the enterprise itself, and also due to the rapid change in economic conditions. At the same time, we made an attempt, based on the above-described scientific experience, to form our own methodological approach of assessing the economic security of industrial enterprises, based on a resource-functional approach.

\section{Methodology}

In Figure 1, we have identified the priorities of the economic security of the enterprise, in accordance with which

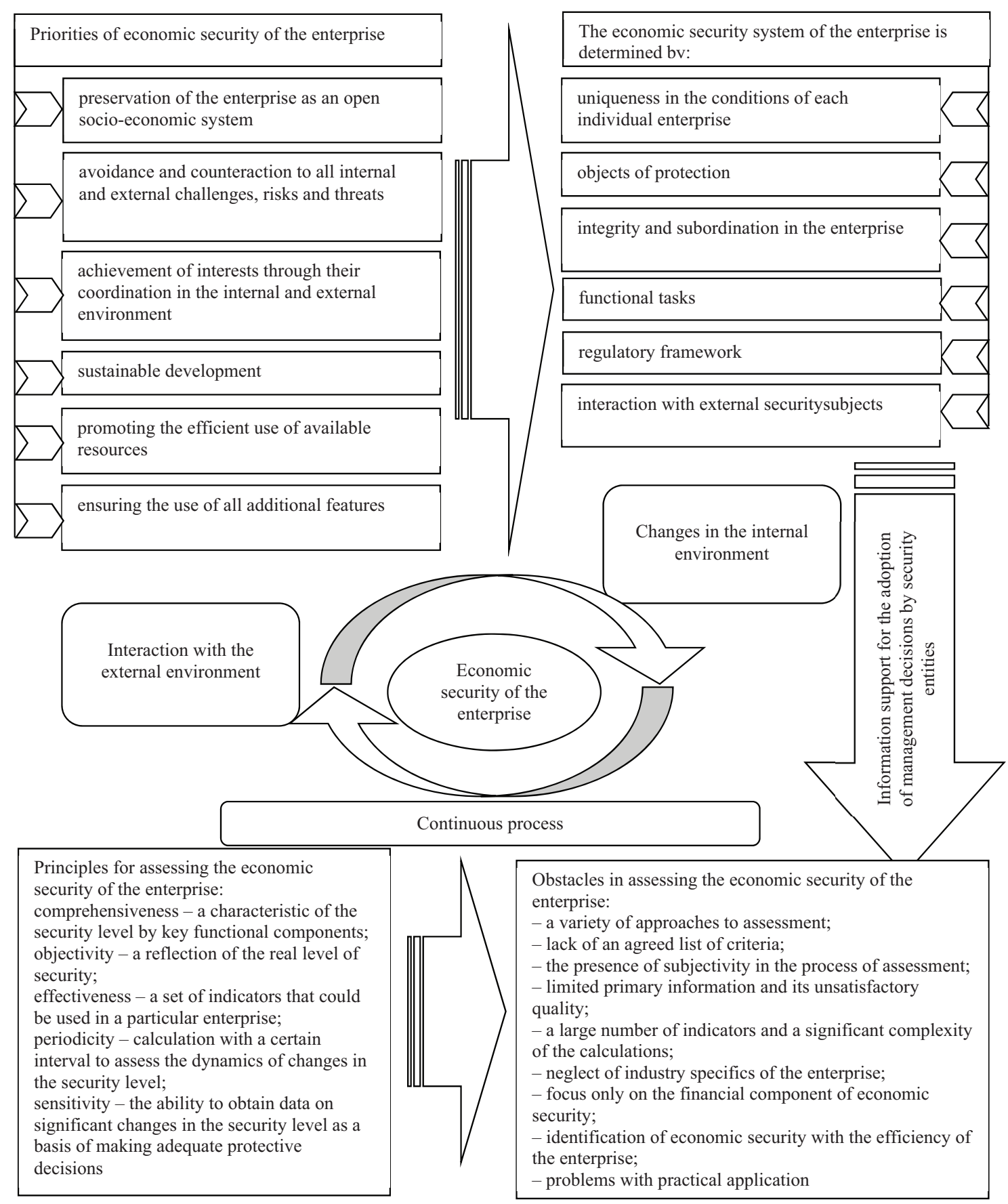

Figure 1. Methodological foundations of the assessment of economic security of the enterprise (source: developed by authors) 
the key parameters of the system of economic security of the enterprise are determined, together proving the importance of informational ground in the formation of safe conditions for the functioning and development of the enterprise. The level of economic security of the enterprise changes continuously as a result of interaction with the external environment and under the influence of internal processes. This continuity requires focusing maximum attention on assessing the level of economic security in each separate period of time in order to develop and implement appropriate protective measures.

\section{Research model}

The sequence of the integrated assessment of economic security of the industrial enterprises is shown in Figure 2.

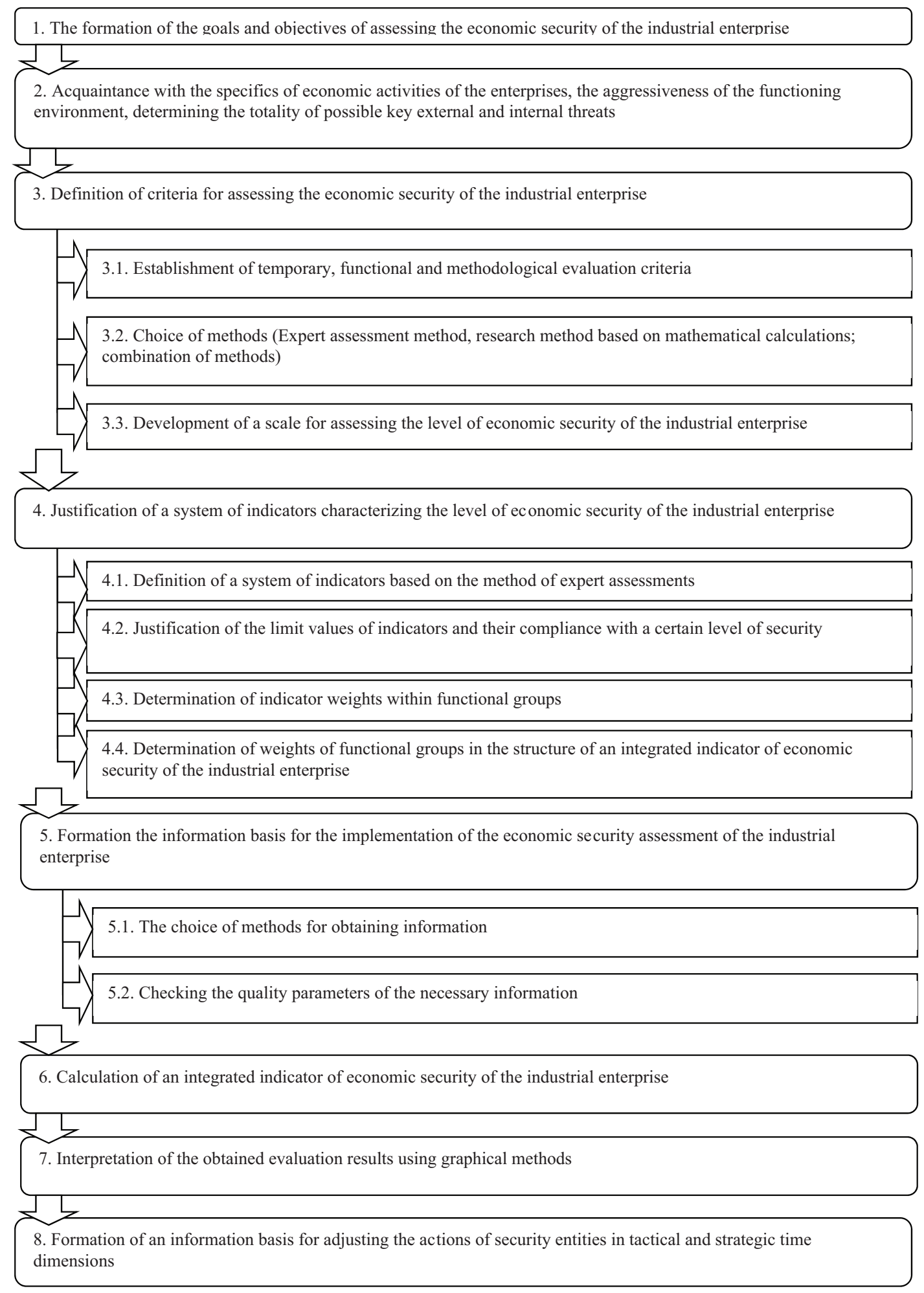

Figure 2. The sequence of integrated assessment of economic security of the industrial enterprises (source: developed by authors) 
Let us to dwell only on a few key points. The first of them is the justification of the system of indicators, which we carried out using the method of expert assessments by forming a group of experts of 25 people. This group includes scientists whose interests include the issues of ensuring economic security, practice, that is, representatives of business circles that belong to the highest level of management of industrial enterprises, and representatives of local authorities in whose territory medium and large industrial enterprises operate. In accordance with the Delphi method, according to their preliminary consent, the formed group was subsequently sent questionnaires to the existing group, which allowed: at the first stage to determine the views of experts on indicators that should be taken into account assessing the economic security of industrial enterprises (the number of indicators was not limited); at the second stage - the points of view were agreed by identifying that part of the indicators that were most often mentioned by experts; at the third stage - the number of indicators is reduced to an acceptable number in terms of reducing the complexity of the calculation and the possibility of practical application at industrial enterprises; at the fourth stage - agreed views on the criteria for assessing the economic security of the enterprise; at the fifth stage, the limit values of the indicators are agreed. Each stage provided the expert with the opportunity to comment on his point of view, reconsider the previous decision, calculate the average group ratings, that is, the arithmetic average of all ratings, weighted average, median and trust quartiles.

We tested the developed methodological approach at ten industrial Ukrainian enterprises: four - oil and gas, three - engineering and three - food industry.

All enterprises, in accordance with the norms of the current legislation, belong to medium and large enterprises. Intermediate calculations are not due to us due to the intricate volume of settlements.

\section{Results and data analysis discussions}

The results of work with experts according to the Delphi method are summarized by us and presented as follows:

- firstly, Figure 3 reflects a set of indicators that are appropriate of use to assess the economic security of industrial enterprises. Each of the functional components is determined by a certain number of indicators, among which there are both quantitative and qualitative. If quantitative are determined by making calculations on the basis of financial and statistical reporting of a certain enterprise, then qualitative ones need an expert survey.

- secondly, Figure 3 in graphical form presents the overall sequence of calculation of the integral indicator of economic security of the industrial enterprises, the basis of which is the weighting coefficients of each indicator, the weighting coefficients of the functional components and the formula for calculation, corresponds to the resource-functional approach to assessing the economic security of the enterprise;

- thirdly, we have developed a methodology for calculating of all indicators; weight coefficients of indicators within the functional groups and limit values of each indicator corresponding to a certain level of safety, corresponding to the results of the expert survey and taking into account the specifics of economic activity of enterprises in the oil and gas, engineering and food industries; methodological foundations for determining the level of security in the context of indicators of economic security for each group of enterprises.

Summarizing, it should be noted that our methodological approach allows to solve some of the significant shortcomings that exist in the above approaches to assessing the economic security of the enterprise as a result of:

- the use of qualitative and quantitative indicators provides an opportunity to obtain a comprehensive description of the level of economic security;

- the ability to determine the level of security at three levels: "indicator" - "functional component" - "integral indicator";

- assessment of the security level by the levels: "high" (0.75-1.0), "medium" (0.5-0.75), "low" (0.25-0.5) and "critical" (0.0-0.25)

- the ability to assess the level of security within the main functional components, which most clearly reflect the essence of economic security of the industrial enterprises;

- the difference in weighting ratios for enterprises in the oil and gas, engineering and food industries, taking into account the specifics of each type of activity and ensure the most reliable results.

We can distinguish the final results of assessing the economic security of industrial enterprises, in particular, the dynamics of the level of security in the context of the main functional components (Figure 4-6). The dynamics of financial security is presented in Figure 4.

According to the results of the calculations, the level of financial security at most industrial enterprises was defined as "medium" or "minimal". At the same time, "critical" was recorded at PJSC "UkrNaftoProbornya" (2014), PJSC “Devon" (2014, 2016-2017), PJSC “Verkhodniprovsky engineering plant" (2017-2018), PJSC "Khurchovik" (2017-2018), PJSC “Nikolaev KH” (2014-2017), to the greatest extent was caused by the loss of business and significant dependence on external sources of financing. A "high" level of security is observed only at PJSC "UkrGasVidobytok" (2014-2016), which was the result of a high indicator - net sales profitability (2014 - 44.18\%; 2015 $46.21 \%$; 2016 - 56, 38\%). Summarizing, it can be argued that financial security, being one of the key for all the studied types of activities, requires special attention from security actors, in particular through the implementation of preventive protective measures. 
The next functional component is personnel, the dynamics of which are reflected in Figure 5.

While the assessing personnel security, quantitative and qualitative indicators were used, therefore, the results were balanced, that is, the calculation results based on statistical reporting and the experts' assessment of the moral and psychological climate and the compliance of workers with the work performed, the degree of satisfaction with working conditions and material remuneration were taken into account. At most industrial enterprises, the level of safety was defined as "low", which was due to high staff turnover (the stability coefficient of the labour collective at

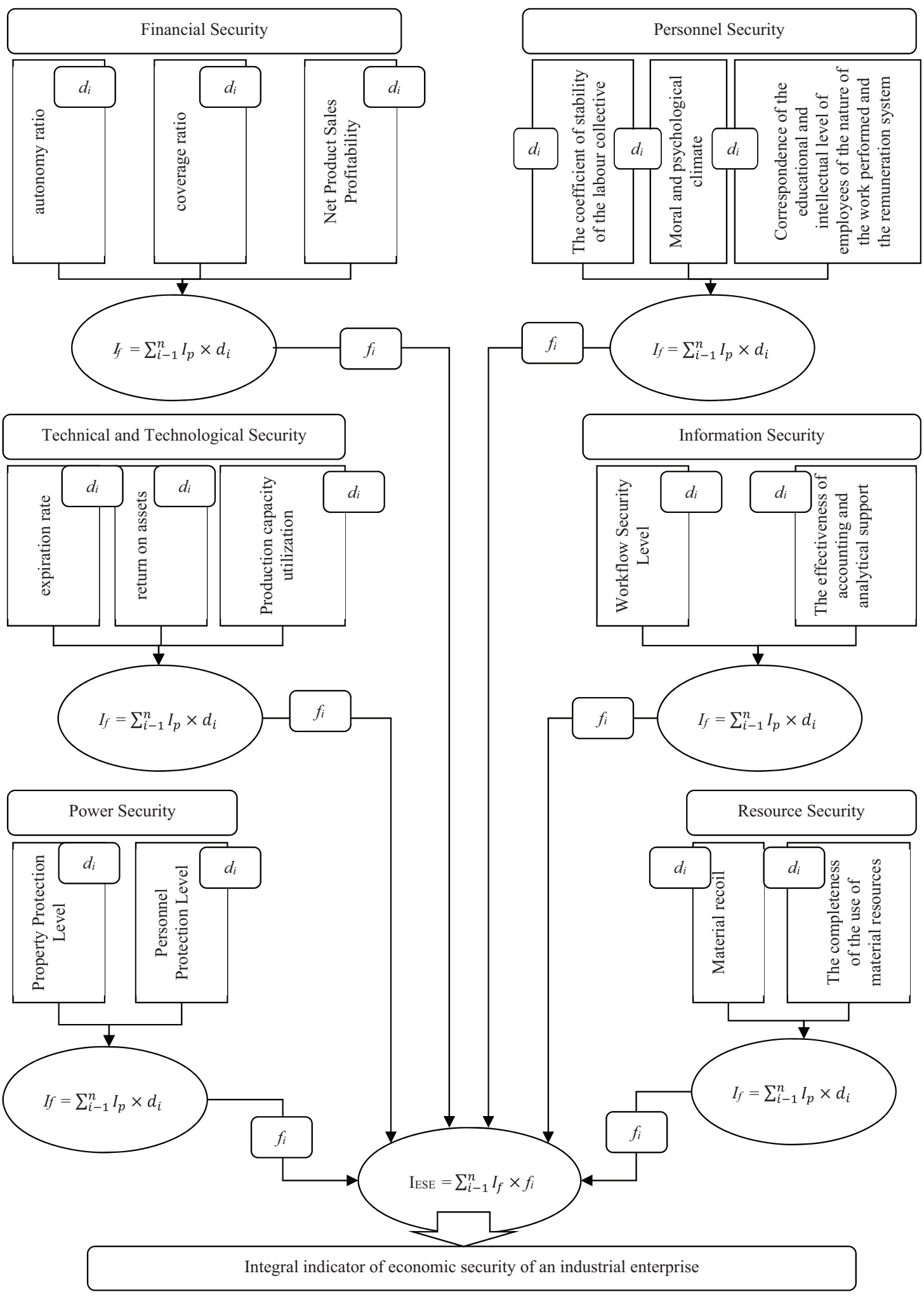

Figure 3. System of indicators of economic security assessment of industrial enterprises (source: developed by authors) 


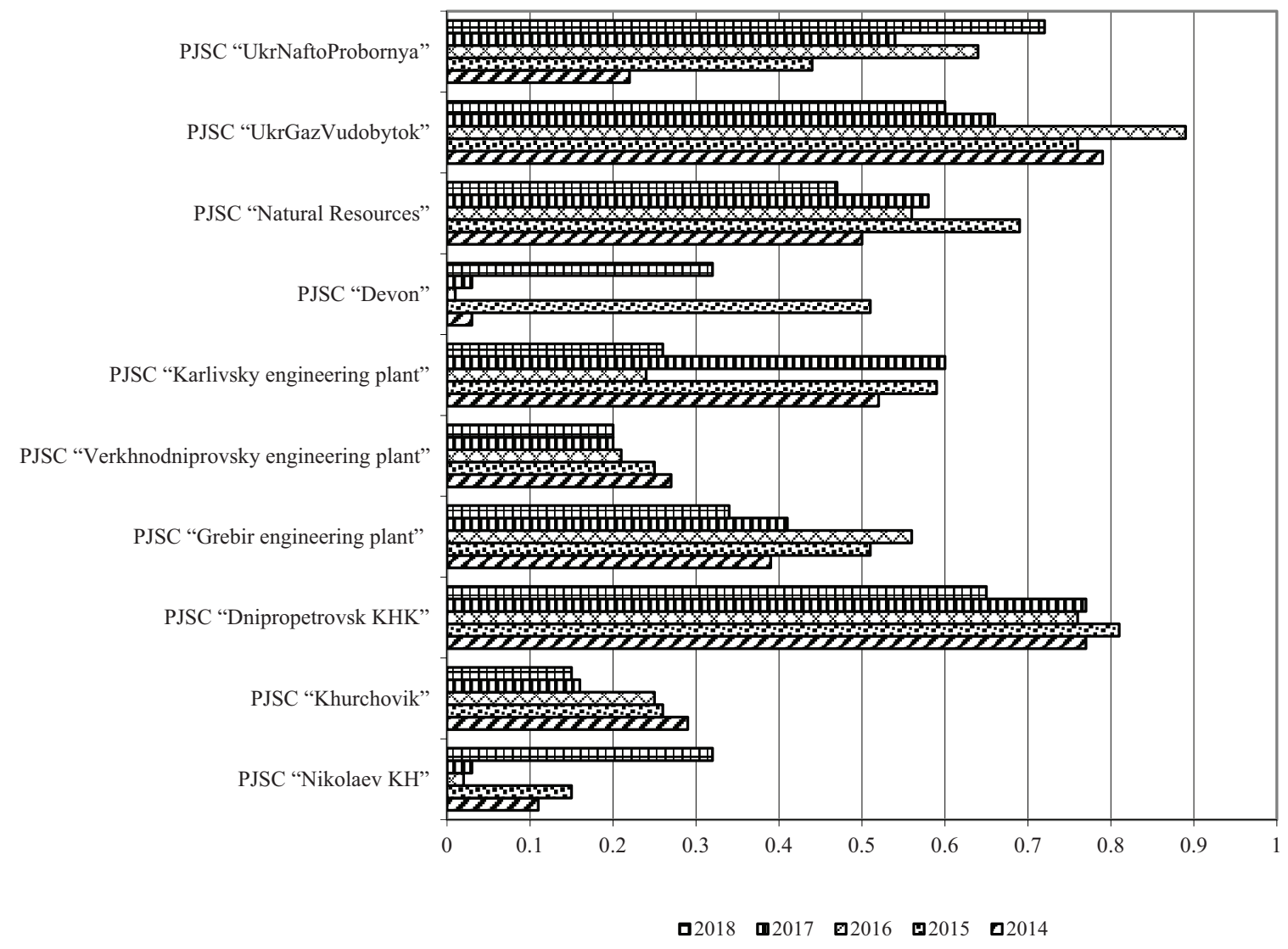

Figure 4. The dynamics of financial security of industrial enterprises (source: developed by authors)

PJSC "Verkhnodniprovsky engineering plant"

PJSC "Grebir engineering plant"

PJSC "Dnipropetrovsk KHK"

PJSC "Khurchovik"

PJSC "Nikolaev KH"

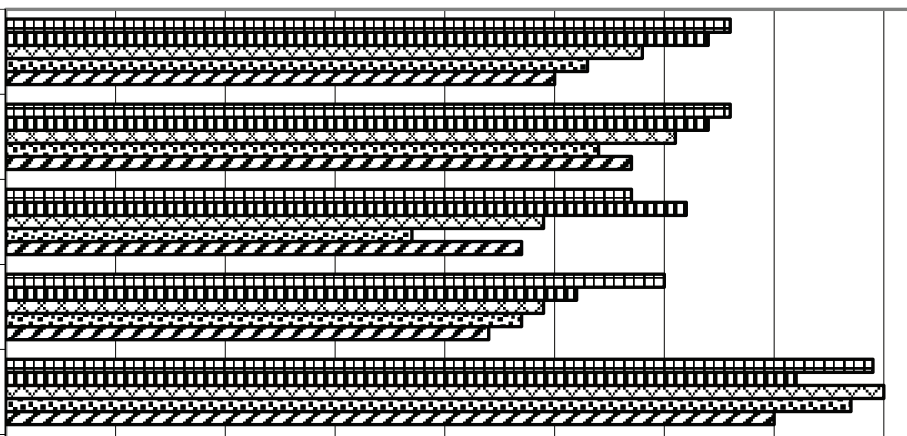

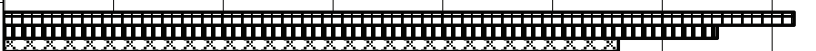

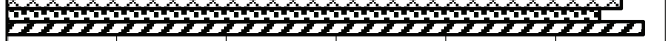

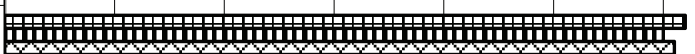
ning

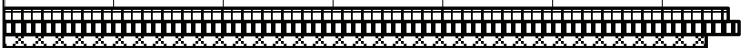

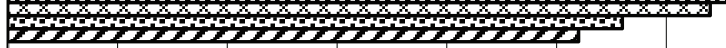

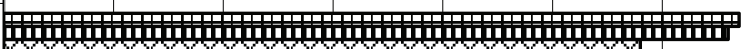

के

سח再 W.t.

0.1

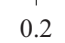

0.3

0.4

0.5

0.6

0.7

0.8

0.9

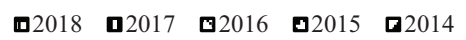

Figure 5. The dynamics of personnel security of Industrial enterprises (source: developed by authors) 
individual enterprises was below 50\%, that is, labour collectives experienced significant personnel changes, negatively affecting both labour productivity and moral and psychological climate, in particular, causing an increase in the number of conflicts and preventing the transfer of accumulated experience from the older generation to the younger), dissatisfaction y conditions and level of remuneration. Experts additionally indicated an increase in the average age of industrial workers, when 50-60 year old specialists dominate among representatives of certain professions, and the number of young specialists is critically low. This problem is especially acute at oil and gas and engineering enterprises, where professional competencies are acquired over a long period of time.

In contrast to personnel security, the dynamics of technical and technological (Figure 6) was characterized by a significant difference in levels.

For example, for CJSC "Natural Resources" the level of this functional component was defined as "medium", and for CJSC "Devon" as "critical", it was mainly caused by a difference in the shelf life of fixed assets (for the first enterprise $-75-85 \%$, for the second $-31-47 \%$ ), magnificent capital productivity (respectively: 1.7-3.15 UAH and 0.18-0.7) and efficient use of production capacities (respectively: "medium" and "low"). Among other enterprises, it is advisable to note the "critical" level of security at CJSC "Nikolaev $\mathrm{KH}$ ", which was the result of a high level of physical and moral depreciation of fixed assets (shelf life - 22-23\%). Despite the fact that the technical parameters of production significantly affect the competitiveness of industrial products not only on the external but also on the domestic market, the threats identified require significant attention from security actors.

The dynamics of information, power and resource security for most enterprises is characterized by a slight change during the study period, and their level was defined as "low" or "medium", which was the result of insufficient attention while the organizing the protection of workflow, property and personnel. Despite the fact that according to the results of expert surveys, the weighting coefficients of these functional components amounted to, compared to the ones considered above, an insignificant share, we consider it advisable to focus on a generalizing indicator, that is, an integral indicator of the economic security of the industrial enterprise (Figure 7).

If we analyse the results of the assessment in the framework of individual enterprises, we can draw the following key conclusions:

- Oil and gas enterprises are characterized by different levels of security and differences in trends. So, for CJSC "UkrNaftoProbornya" the security level was determined in 2014-2015 - "low", but in 2015-2018

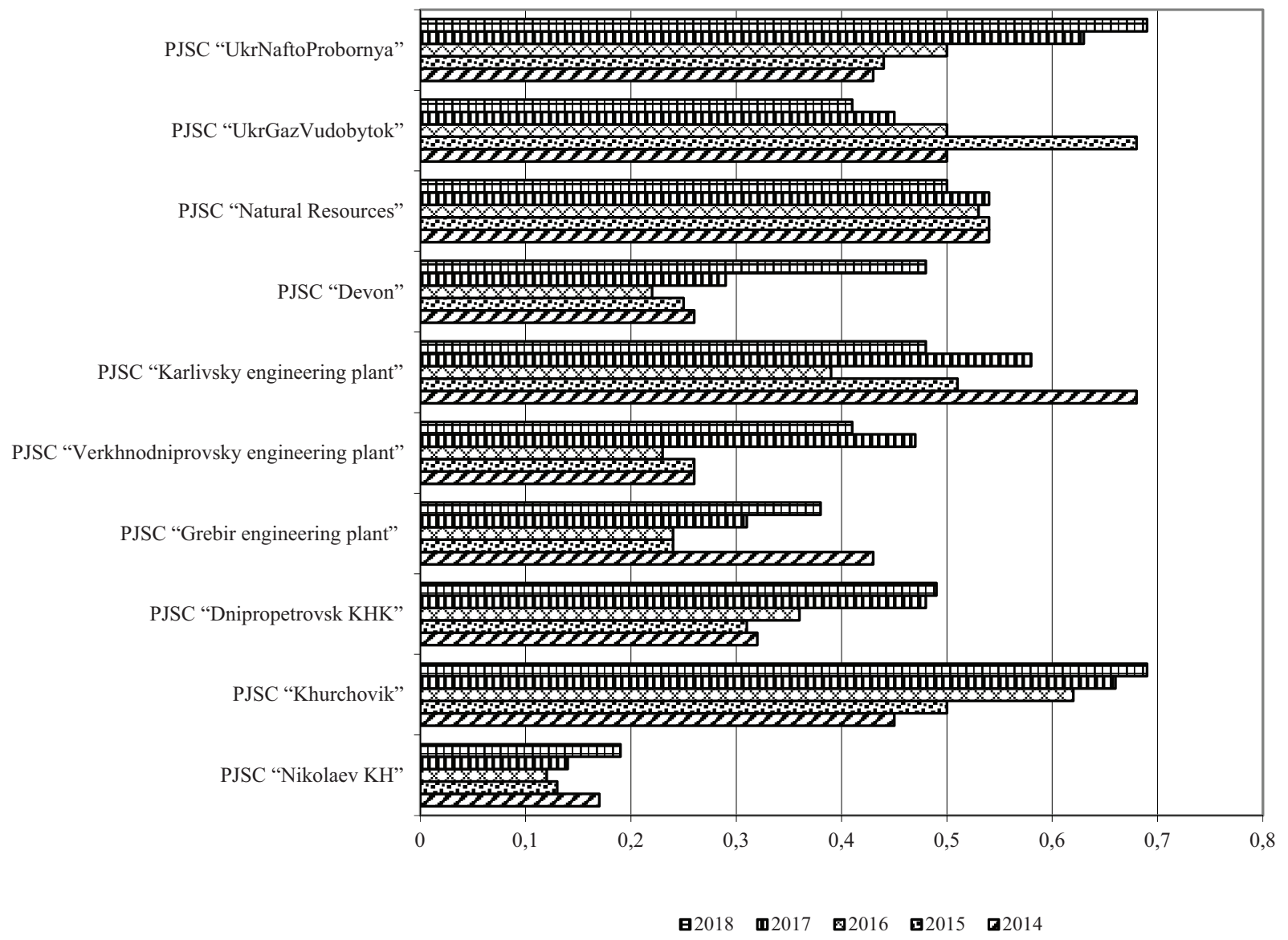

Figure 6. The dynamics of technical and technological security of industrial enterprises (source: developed by author) 


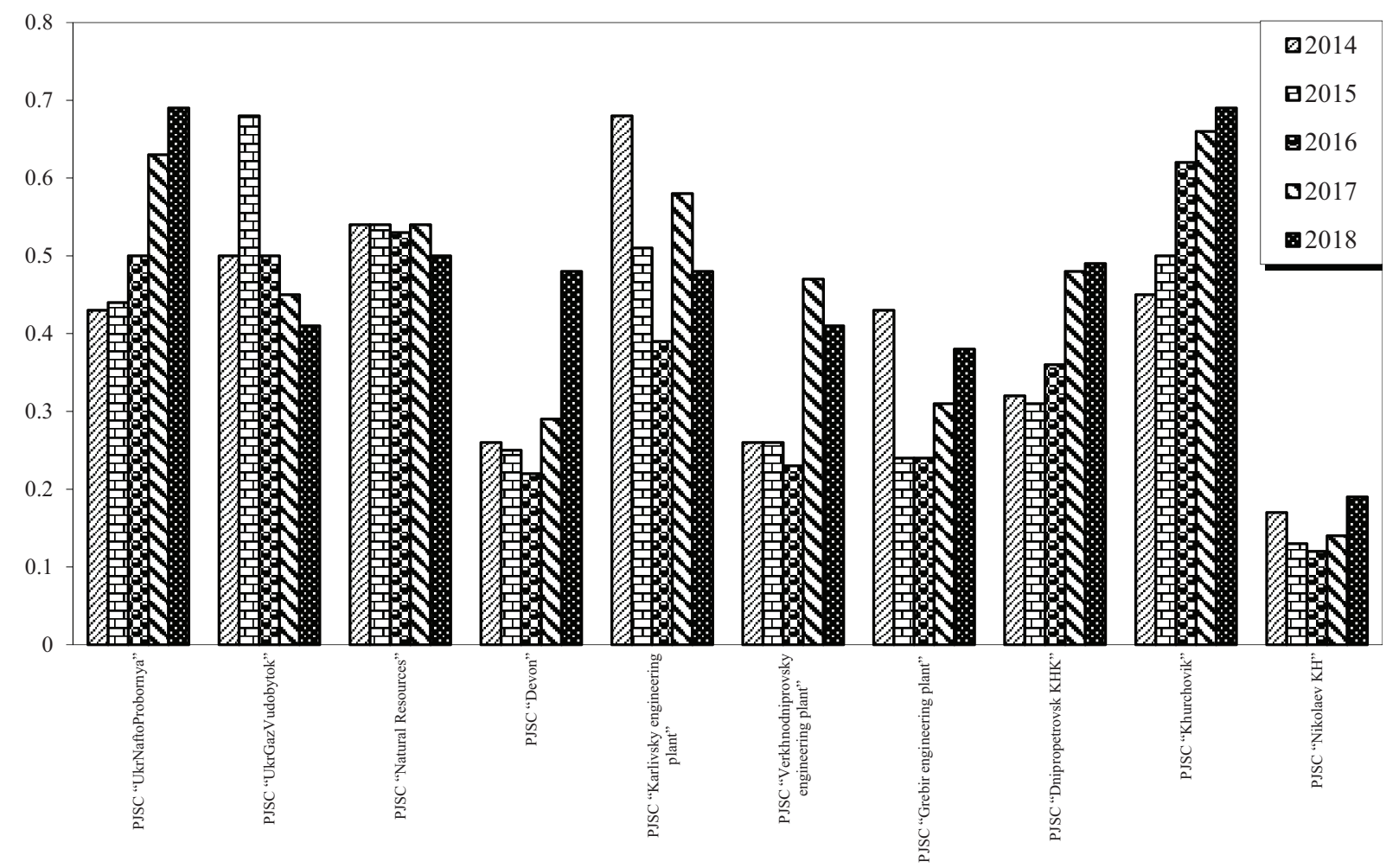

Figure 7. Dynamics of an integrated indicator of economic security of industrial enterprises (source: developed by author)

- "medium" and positive dynamics of the integral indicator - an increase from 0.4 to 0.64 . For CJSC "UkrGasVydobytok", despite the "medium" level of security, the value of the integral indicator has a dynamics to decrease, that is, from 0.61 in 2015 to 0.53 in 2018. The level of economic security of CJSC "Devon" was defined as "low";

- if the engineering enterprises of Karlovsky MZ OJSC and Grebinkovsky MZ OJSC are characterized by fluctuations in the integral indicator within the "medium" and "low" level of security, then the economic security for PJSC Verkhnedneprovsky LMZ was defined as "low";

- for CJSC “Dnipropetrovsk KHK” and CJSC "Nikolaev $\mathrm{KH}$ ", the security level was relatively stable, respectively, at the level of "medium" and "low", when for JSC "Khurchovik" it fluctuated between these values;

- None of the enterprises studied was characterized by a "high" level of economic security, when for the majority it was defined as "low".

\section{Discussions}

As a result of practical application, we proposed an improved approach, which provides for the determination of the security level at three levels: "indicator - functional component - financial indicator" and allows to obtain reliable information about the economic security of oil and gas, engineering and food industries by taking into account the specifics of their economic activities and differences in safety in determining weights and threshold indicators torus, serves as the basis for the adoption of tactical and strategic decisions by security entities. Which, after practical application at Ukrainian enterprises, can be implemented for other enterprises in Eastern Europe.

The application of our model in Ukrainian enterprises may be useful for other European enterprises, especially for industrial enterprises in Eastern Europe (Figure 8).

Our proposed model of assessing economic security will be useful to managers of industrial enterprises in Europe who are planning or have already phased out subsidiaries in Ukraine. The close interaction of Ukraine with other countries of Eastern Europe is confirmed by the fact that European enterprises that plan to enter the Ukrainian market need to adapt development to new conditions. In such conditions, our model will be effective.

It has been established that the scientific literature contains a rather significant number of different approaches to assessing the economic security of the enterprise, creates ambiguity and hinders their practical application. A critical analysis of key approaches was carried out, which allowed us to characterize their methodological foundations and identify certain shortcomings that impede the active use of industrial enterprises in the process of ensuring the economic security.

A sequence of integrated assessment of the economic security of industrial enterprises is proposed, which consists of eight stages, which include: studying the specifics of economic activity and the process of ensuring the security of a given enterprise, determining a system of 


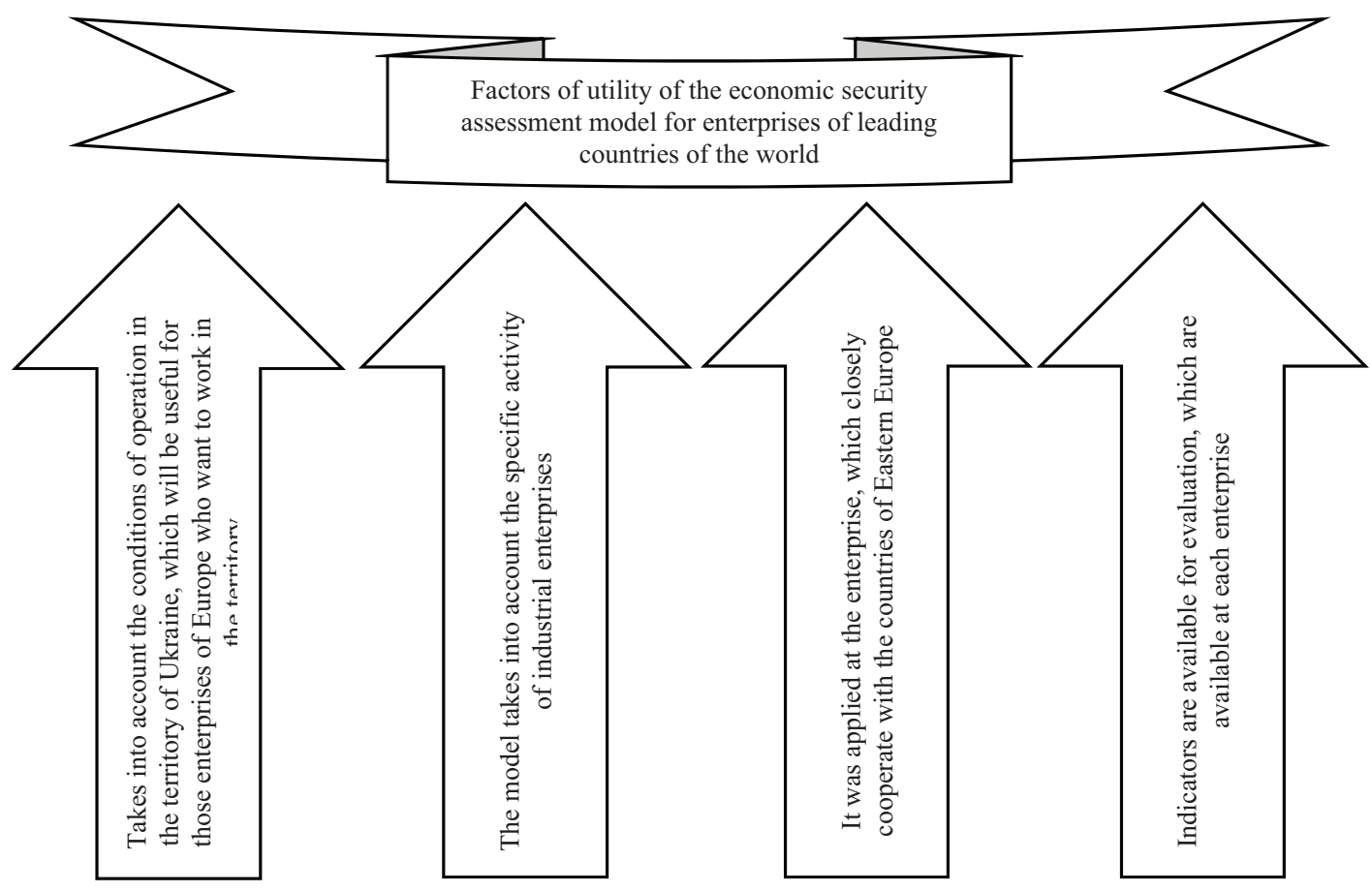

Figure 8. The main factors under which a model for assessing economic security can be useful for enterprises in Eastern Europe (source: developed by author)

indicators, choosing a method for obtaining information, calculating an integral indicator and interpreting the results of the assessment, as a result it allows to form methodological approach of assessing the economic security of industrial enterprises.

\section{Conclusions}

A methodological approach of assessing the economic security of industrial enterprises has been developed that allows: determining the level of security at three levels: "indicator" - "functional component" - "integral indicator"; carry out a safety assessment according to the levels: "high", "medium", "low" and "critical"; to obtain reliable results on the level of economic security of oil and gas, engineering and food industry enterprises taking into account specifics while the determining weighting factors and threshold indicators.

The results of testing the developed methodological approach in ten industrial enterprises showed that there are threats in the field of financial security due to unprofitable economic activity and significant dependence on external sources of financing, human security due to high staff turnover, technical and technological, which is caused by a critical level of physical and moral depreciation fixed assets and used technologies. The data obtained are the basis for improving the management of economic security of industrial enterprises, including through the development by security entities of tactical and strategic decisions in the process of ensuring the safety of industrial enterprises.
It is proved that the effectiveness of ensuring the economic security of industrial enterprises is determined by the quality of the information basis for the actions of security entities. A methodological approach is proposed that provides for the determination of the security level at three levels: "indicator - functional component - financial indicator" and allows you to obtain reliable information about the economic security of oil and gas, engineering and food industries by taking into account the specifics of their business activities and differences in safety in determining weighting factors and threshold indicators, serves as the basis for making tactical and strategic decisions subjects of security.

\section{Limitations and future research directions}

The study is not without limitations. At this point in time, the proposed model for assessing economic security can be applied only to the industrial enterprises. In the future, it is necessary to expand the number of indicators and attract enterprises of another industry.

\section{Author contributions}

The authors contributed equally.

\section{Disclosure statement}

The authors do not have any conflict of interest. 


\section{References}

Avanesova, N., \& Chuprin, Y. (2017). Enterprise economic security: essential characteristics of the concept. Innovative Technologies and Scientific Solutions for Industries, (1), 98-102. https://doi.org/10.30837/2522-9818.2017.1.098

Arefieva, O. V., \& Kuzmenko T. B. (2005). Planning of economic security of enterprises (pp. 17-18). Kiev: Publishing House of Europe.

Biliomistniy, O., Bilomistna, I., \& Galushko, Y. (2017). Influence external and internal factors to financial security of enterprise. Financial and Credic Activity: Problems of Theory and Practice, 1(22). https://doi.org/10.18371/fcaptp.v1i22.109935

Burkaltseva, D., Borsch, L., Blazhevich, O., Frolova, E., \& Labonin, I. (2017). Financial and economic security of business as a primary element in the economic system. Revista: Espacios, 38(33), 3-20.

Britchenko, I., Bohomolova, N., Kravchenko, O., \& Pinchuk, S. (2018). Assessment of the determinats of financial security of railways in Ukraine. Financial and credit activity: Problems of Theory and Practice, 4(27). https://doi.org/10.18371/fcaptp.v4i27.154109

Bublyk, M., Koval, V., \& Redkva, O. (2017). Analysis impact of the structural competition preconditions for ensuring economic security of the machine building complex. Marketing and Innovation Management, 4. https://doi.org/10.2139/ssrn.3184338

Bendikov, M., \& Khrustalev, E. (1999). Economic safety of hightech industries. Economic Issues, 9, 9-16.

Blank, I. A. (2004). Financial strategy of the enterprise (pp. 7273). Kiev: Nika-Center, Elga.

Bandurka, A. M., Dukhov, V. E., Petrova, K. Ya., \& Chervyakov, I. M. (2003). Fundamentals of economic security: textbook (p. 236). Kharkov: Publishing House of the National. University of Internal affairs.

Evdokimov, F. I., Mizina, E. V., \& Borodina, A. A. (2002), Generalizing assessment of the financial level of the economic security of an enterprise. Economic Journal DNTU, 47, 6-12. Donetsk: Publishing house of DonNTU.

Franchuk, V., Omelchuk, O., Melnyk, S., Kelman, M., \& Mykytyuk, O. (2020). Identification the ways of counteraction of the threats to the financial security of high-tech enterprises. Business: Theory and Practice, 21(1), 1-9. https://doi.org/10.3846/btp.2020.11215

Farber, V. (2018). Financial aspects of economic security. ITMO Scientific Journal, Series of Economics, 4, 54-55. https://doi.org/10.17586/2310-1172-2018-11-4-52-61

Ianioglo, A., \& Polajeva, T. (2017). The essence and phases of the comprehensive system of ensuring the economic security of enterprise, International Journal of Learning and Change, 9(1), 59-74. https://doi.org/10.1504/IJLC.2017.10005203
Ilyashenko, S. N. (2002). Assessment of the components of the economic security of an enterprise. Scientific DonNTU, 48, 16-22. Donetsk.

Khalina, O., Bazyliuk, V., Chornenka, O., Krasilych, I., \& Korzh, M. (2019). Formation of organizational support for the management of the economic security of engineering enterprises: methodical and practical aspects. Business: Theory and Practice, 20, 317-328. https://doi.org/10.3846/btp.2019.30

Kovalev, D., \& Pletnikova, I. (2000). Quantitative assessment of the level of economic security of an enterprise. The Economy of Ukraine, 4, 35-40.

Kozachenko, G. V. (2013). Economic security as a fundamental category of bespecology. Safetylessness: Theory and Practice: Materials of the I All-Ukrainian Scientific-practical Conference (p. 332).

Kljucnikov, A., Mura, L., \& Sklenar, D. (2019). Information security management in SMEs: factors of success. Entrepreneurship and Sustainability Issues, 6(4), 2081-2094.

https://doi.org/10.9770/jesi.2019.6.4(37)

Menggang, L. (2013). Research on industrial security theory (p. 442). Springer Heidelberg. New York, Dordrecht, London.

Ortinsky, V., Kernitsky, I., \& Zhivko, Z. (2009). Economic security of enterprises, organizations and institutions: textbook. allowance. for study higher textbook. Bookmark (pp. 54-56). Kiev: All-Ukrainian. Asoc. Publishers of Legal Unity.

Pokropivny, S. (2000). Business economics (pp. 17-24). Textbook. allowance. Kiev: KNEU.

Sylkin, O., Kryshtanovych, M., Zachepa, A., Bilous, S., \& Krasko, A. (2019). Modeling the process of applying anti-crisis management in the system of ensuring financial security of the enterprise. Business: Theory and Practice, 20, 446-455. https://doi.org/10.3846/btp.2019.41

Stavytskyi, O. (2017). Formation of a model of economic security. National Technical University of Ukraine "KPI named Igor Sikorsky". http://ela.kpi.ua/bitstream/123456789/23882/1/S.71-77.pdf

Sitdikova, L. B., \& Starodumova, S. J. (2019). Corporate agreement as a means of providing security in the course of entrepreneurship development. Entrepreneurship and Sustainability Issues, 7(1), 324-335. https://doi.org/10.9770/jesi.2019.7.1(24)

Wu, Y., \& Meng, F. (2019). Categorizing security for security management and information resource management. Journal of Strategic Security, 11(4), 72-84. https://doi.org/10.5038/1944-0472.11.4.1694

Zhivko, Z. (2013). Methodology of management of economic security of an enterprise (monograph) (pp. 48-92). Liga-Pres, Lviv.

Zabrodsky, V. A., \& Kizim, N. A. (2000). Property, economic security and the state. Economic Cybernetics, 3-4, 58-63. 